\title{
Microsurgical anterior cervical approach and the immediate impact of mechanical retractors. A case-control study
}

This study was based on the known high rate of immediate complications after anterior cervical discectomy and fusion (ACDF) including soft tissue problems such as dysphagia, dysphonia, esophageal lesions, and local hematoma. ${ }^{[1]}$ The design of this evaluation was retrospective and case controlled, dealing with 37 patients who were comparatively analyzed after changes in the retraction method. Interestingly, the rate of immediate soft tissue problems could be significantly decreased from $94.1 \%$ to $5.1 \%$ after the use of only manual protective blades in contrast to automatic mechanical retraction.

These findings are very important and valuable for all spine surgeons because most of them probably use automatic mechanical retracting systems due to its easy handling. However, they should be aware of the potential risks for soft tissue problems, and the patients have to be informed about this before operation. It seems to be so easy to reduce these complications just with the use of only manual protective blades.

However if the surgeon uses automatic mechanical retractors there are some relevant points, which should be considered to decrease the complication rate nevertheless. First, the technique of preparation to perform the anterolateral approach to the cervical spine should be as mild as possible, meaning only dissection of the medial structures (trachea, esophagus) from the

\begin{tabular}{|l|l|}
\hline \multicolumn{2}{|c|}{ Access this article online } \\
\hline Quick Response Code: & Website: \\
\hline & www.ruralneuropractice.com \\
\cline { 2 - 3 } & \\
\hline & \\
\hline
\end{tabular}

lateral vessel-nerve-bundle in a blunt way with the use of one finger, a retractor and compact sponges. Second, it is recommended then to distract the blades during the whole operation only as much as necessary in order to expose the disc space with its both margins because this space is generally enough to perform ACDF (with or without a plate) and it will help to avoid too much soft tissue irritation during a longer time period or in a multilevel procedure. Third, the anesthesiologist can reduce the pressure of the tracheal tube cuff after the distraction of the retractor blades, which especially can decrease the risk of dysphonia due to a lesion of the recurrent laryngeal nerve.

Nonetheless, the commentator believes, that at least slight complaints like dysphagia cannot completely be avoided in spite of all prevention measures particularly in multilevel operation and longer operation time or revision surgery with preexisting tissue scars, but that in most cases the discomfort has a very good prognosis with remission during a short time.

Dorothea Daentzer Department of Orthopedic, Spine Section, Hannover Medical School, Diakoniekrankenhaus Annastift $\mathrm{gGmbH}$

Address for correspondence: Dr. Dorothea Daentzer, Anna-von-Borries-Str. 1-7, 30625 Hannover, Germany. E-mail: dorothea.daentzer@ddh-gruppe.de

\section{Reference}

1. Ramos-Zuñiga R. Microsurgical anterior cervical approach and the immediate impact of mechanical retractors. J Neurosc Rural Pract 2015;6:315-9.

How to cite this article: Daentzer D. Microsurgical anterior cervical approach and the immediate impact of mechanical retractors. A case-control study. J Neurosci Rural Pract 2015;6:297.

Source of Support: Nil. Conflict of Interest: None declared. 